\title{
Corpo, Artes e Espiritualidade no Trabalho de François Delsarte (1811-1871): uma dinâmica da educação somática expressiva
}

\author{
Franck Waille* \\ E-mail: franck.cw@gmail.com \\ Tradução: Leela Alaniz \\ E-mail: leela@pasdedieux.com
}

Este artigo sintetiza as pesquisas que Franck Waille realizou em torno de François Delsarte entre 2003 e 2013. Estas pesquisas tomaram a primeira forma com a defesa da primeira tese em francês sobre Delsarte em 2009, centrada nas interações dinâmicas entre o corpo, artes e espiritualidade no trabalho de Delsarte. O último trabalho de Waille sobre a questão destaca a dimensão somática dos ensinamentos expressivos delsartianos.

Palavras-chave

Delsarte. Educação Somática. Espiritualidade.
Cet article synthétise les recherches que Franck Waille a mené autour de François Delsarte de 2003 à 2013. Ces recherches ont pris une première forme avec la soutenance de la première thèse en français sur Delsarte en 2009, centrée sur les interactions dynamiques entre le corps, les arts et la spiritualité chez Delsarte. Le dernier ouvrage de F. Waille sur la question met en valeur la dimension somatiques des enseignements expressifs delsartiens.

Mots clés

Delsarte. Éducation Somatique. Spiritualité.

\footnotetext{
* Franck Waille, professor e pesquisador associado ao Laboratório de Pesquisa Histórica Rhône-Alpes (LARHRA), é autor de Corps, arts et spiritualité chez François Delsarte (1811-1871). Des interactions dynamiques (2009), primeiro doutorado em francês sobre Delsarte. Ele dá palestras e cursos de prática corporal expressiva Delsarte pela Cia. Chorâme, criada em 2012. É autor de artigos em francês, inglês e português sobre Delsarte. Dirigiu: Trois décennies de recherche européenne sur François Delsarte (L'Harmattan, 2011) e dirigiu, em parceria: François Delsarte, une recherhce sans fin (L'Harmattan, 2015). Seu último trabalho, La méthode somatique expressive de François Delsarte. Histoire, esthétique, anthropologie: de la neurophysiologie à la métaphysique foi publicado pela L'Entretemps em 2016. Ele completou um pós-doutorado na Universidade de Quebec em Montreal no Departamento de Dança (2014-2015) e, atualmente, realiza outro pós-doutorado na Faculdade de Educação da Universidade Federal do Rio Grande do Sul.
} 


\section{Introdução}

François Delsarte, francês, cantor, professor de canto e de declamação, com fama primeiramente na Europa, deixa uma herança rica, complexa e versátil de vital importância para as artes cênicas do século XX. Ele "foi o primeiro a realizar uma pesquisa aprofundada sobre os movimentos, gestos e expressões do corpo humano" (BARBA; SAVARESE, 2008, p. 167), e "geralmente concordamos em situar o início das artes cênicas modernas no momento de suas primeiras pesquisas e de seu ensinamento [...] sobre o corpo e sua linguagem" (BOURRASSA, 1987, p. 16). Seus ensinamentos produziram uma verdadeira Delsartemania póstuma nos Estados Unidos nas últimas décadas do século XIX e, em geral, através dos vários alunos de Delsarte, tiveram uma influência em todo o mundo entre os pioneiros do teatro e da dança moderna.

No campo da arte dramática (e depois do cinema), o legado de Delsarte é, pelo menos, controverso. Alguns o consideram como a origem de uma prática artística rígida e monstruosamente mecânica ${ }^{1}$, enquanto outros o veem como o início da modernidade, particularmente pela nova abordagem do corpo no trabalho do ator. Porém, sua relação como campo da dança é bastante diferente, sendo um campo completamente estranho às preocupações di-

1 Jacques Aumont, um dos maiores teóricos do cinema moderno, escreveu: "O trabalho de François Delsarte (...) propõe um "método" fundamentado na fisionomia e, tendo em sua base um tipo de dicionário ou léxico que estabelece uma correspondência entre gestos e estados mentais: há um caminho, e apenas um, para o corpo manifestar raiva, angústia, ciúme, ansiedade ou ternura. A cada emoção corresponde um movimento do corpo; e, inversamente, um movimento do corpo representa adequadamente uma única emoção. Jogar é, de acordo com o sistema da pantomima, aprender a produzir "enunciados bem formados" em uma linguagem convencional e artificial que mobilize o corpo. (Jacques Aumont, Le cinéma et la mise en scène, Armand Colin, 2006, p.20). retas desse artista e, no entanto, sendo o que melhor recebeu e desenvolveu seu trabalho. ${ }^{2}$ Por outro lado, uma das tendências da historiografia americana é reduzir o ensino de Delsarte ao canto e a uma abordagem essencialmente teórica das realidades expressivas, atribuindo, assim, aos seus herdeiros americanos, os aspectos práticos essenciais de um sistema expressivo complexo, baseado em uma tabela teórica bem construída, e relativamente desconcertante à primeira vista, porque é essencialmente estruturado em torno de conceitos metafísicos.

Este legado multifacetado e contrastante orienta, inevitavelmente, a abordagem do historiador para o ensinamento de origem, em uma perspectiva dupla: tentar fazer uma triagem separando aquilo que foi atribuído a Delsarte, daquilo que ele realmente ensinou, $e$ para entender a dinâmica interna de seu trabalho, retornando aos fundamentos históricos, biográficos, práticos e teóricos deste trabalho. Uma dificuldade metodológica surge imediatamente: a ambição é voltar a uma prática viva essencialmente transmitida oralmente, através de uma transmissão direta do mestre aos discípulos, mas da qual permanece hoje vestígios na forma de documentos escritos (várias publicações dos alunos) e fontes que podemos chamar de "semi-orais": as anotações diretas dos alunos tomadas durante os ensinamentos de Delsarte e as próprias anotações deste (que nunca publicou algo referente ao seu trabalho).

2 "Se, como relata Nancy Lee Chalfa Ruyter ..., a linhagem teatral de Delsarte viu em seu sistema 'uma fórmula rígida e mecânica de expressão', podemos dizer como Odette Aslan que serão os bailarinos que 'entenderão melhor as ideias de Delsarte e irão livrá-las de qualquer ideia de pathos e cliché'”. (Christophe Damour, "L'influence de Delsarte sur le jeu de l'acteur aux États-Unis", in L'acteur de cinema: approches pluridisciplinaires, Actes du colloque international tenu en octobre 2005 à Cerisy, Presses universitaires de Rennes, 2007, p. 20). 
Isso implica uma demanda metodológica: tentar abordar os escritos levando em consideração "a vida que os fertiliza" 3 de acordo com a expressão do artista. Isso implica colocar todos os documentos na visão estética geral de Delsarte, tanto teórica como prática, e abordá-la não só com as ferramentas da análise científica intelectual, mas também com as de uma prática artística, especialmente vocal e corporal. Antes de nossa pesquisa, apenas um trabalho científico foi baseado nos manuscritos de Delsarte. ${ }^{4}$ Trata-se de prolongá-lo, concentrando-se no que caracteriza os ensinamentos expressivos de Delsarte: a articulação de questões corporais, espirituais e artísticas.

Nossa tese geral é de que esses ensinamentos se centraram no trabalho do corpo, porque o canto implica o corpo como um instrumento e se baseia em uma pedagogia artística voltada para a liberdade dos alunos e não para a codificação das expressões. Os trabalhos anteriores ao nosso e os arquivos consultados nos permitiram destacar o fato de que Delsarte, através de suas experiências iniciais - aos 18 anos perda de uma voz promissora, auto reeducação vocal, inúmeras observações das correlações entre gestos e emoções -, desenvolveu um método empírico para a observação de realidades expressivas, que continua sendo a referência fundacional de seu trabalho.

Suas observações levaram-no a construir uma tabela teórica de explicação dos fenômenos observados, sobretudo com vista à eficácia pedagógica. $\mathrm{O}$ trabalho prático e a reflexão

3 Carta de Delsarte a Mackaye em 9/10/1870 (conservada no The papers of the Mackaye Family, Baker Library, Special collections, Dartmouth College, Hanover, New Hampshire, box 22 , folder 3 ,documento 3 ).

4 Elena Randi, L'estetica di François Delsarte: la dimensione spettacolare, tese de doutorado em Teoria e Historia da representação, universidade de Padoue, Padoue, 1992. estética levaram-no a considerar as realidades expressivas, o ato artístico e o corpo humano intimamente associados a uma dimensão espiritual e metafísica, na qual ele afirma ter encontrado o critério para entender as realidades expressivas. Como resultado da sua conversão ao catolicismo, mas também dos múltiplos ambientes de formação que encontrou (maçonaria iluminista, esoterismo cristão, professores de latim e de hebraico, em particular, introdução à Cabala), essa dimensão espiritual e a metafísica misturam a teologia católica e o pensamento esotérico antigo e medieval. Seus ensinamentos propõem concentrar os dados metafísicos utilizados no trabalho expressivo.

Além disso, a dinâmica pedagógica de Delsarte é diretamente inspirada em seu próprio método empírico de observação das realidades expressivas, nele mesmo e ao seu redor. Essa dinâmica pedagógica é sintetizada por esta frase-chave:“Um aluno do meu método é um observador silencioso dos fenômenos que o cercam e se manifestam dentro de si mesmo" (DELSARTE, 1992, p. 260).

Esta dinâmica pedagógica prefigura a abordagem contemporânea chamada educação somática. Desde o final da década de 70 , o termo "somático" (da raiz grega sôma, corpo) procura escapar do dualismo alma/corpo (do latim corpus) e se refere à auto percepção na primeira pessoa em movimento ("eu", não "ele/ ela"), a partir de uma perspectiva integrada das diferentes dimensões do indivíduo. ${ }^{5}$ Tudo isso está no centro da abordagem delsartiana das realidades expressivas.

5 Cf. Thomas Hanna, The Body of Life, New York, Alfred A. Knopf, \& "What is Somatics?" Somatics: Magazine-Journal of the Bodily Arts and Sciences, vol. V, no 4, Spring-Summer 1986, p. 4-8 (http://somatics.org/library/htl-wis1.html). 


\section{Conhecer a tabela teórica de} Delsarte torna possível compreender melhor seu trabalho prático

O conhecimento preciso de sua tabela teórica evita alguns dos mal-entendidos e deformações que acompanharam a difusão de seus ensinamentos. Assim, a ferramenta sintética, por excelência, de Delsarte é o que ele chamou de "nono acorde", que o serviu para analisar qualquer realidade e, em particular, as realidades expressivas. Podemos dar o seguinte exemplo para a mão, publicado por um de seus alunos, o abade Delaumosne (outras publicações do mesmo acorde, por outros herdeiros de Delsarte, apresentam tabelas bem diferentes):

Figura 1: Nono acorde de mãos, Abbé Delaumosne, Pratique de l'art oratoire de Delsarte, 1874

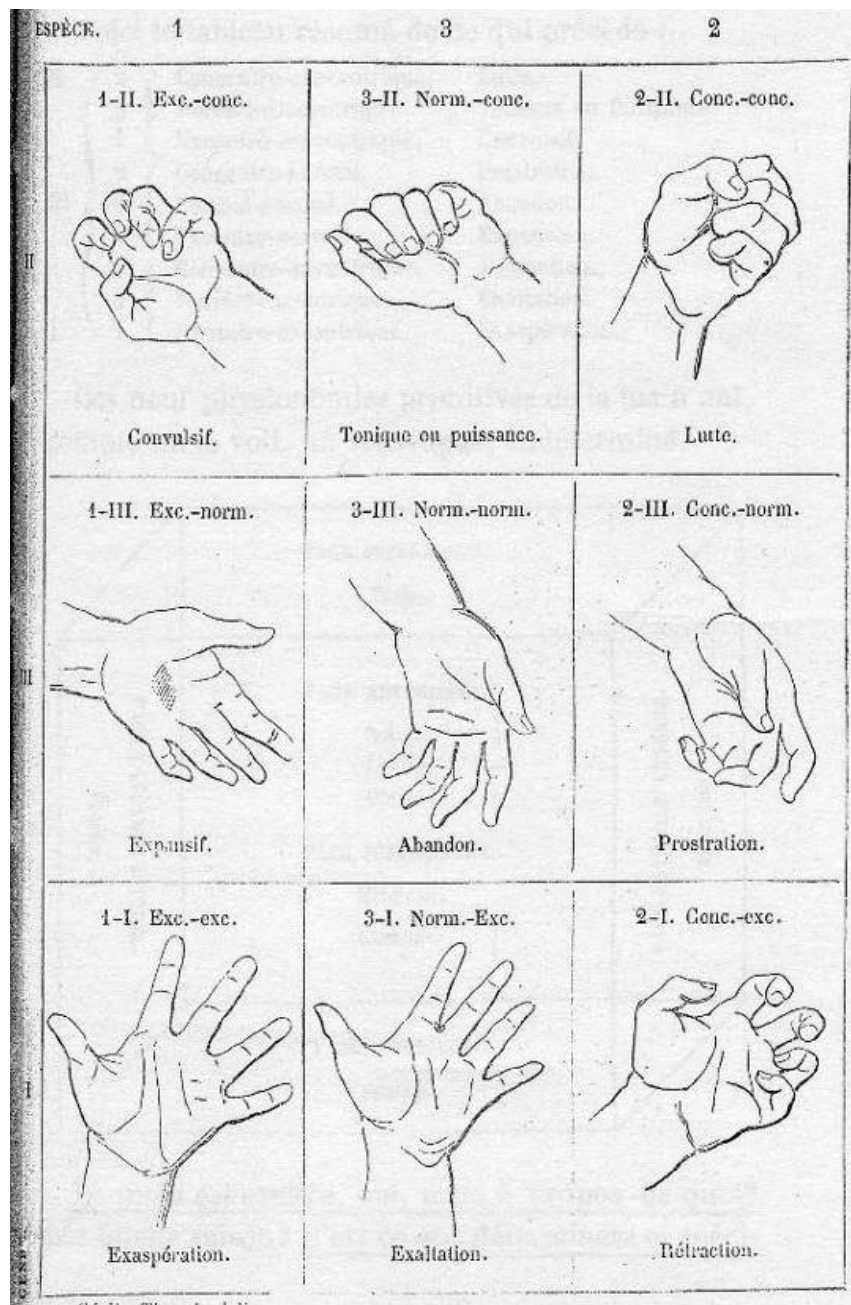

Delsarte, durante um curso em 1859, advertiu: "Onde aprendemos la mimique ${ }^{6}$ ?" Seria no livro que Lebrun chamou de Les Passions (1698) e onde, mostrando um tipo, ele disse:

Aqui está o amor? O amor, uma substância escondida, visível apenas pelas expressões sensoriais que correspondem a um número ilimitado de transformações das quais você é suscetível e que dá tantas fisionomias diferentes, reduziram-no a um termo, aqui o mediram, você que é o infinito!"?.

Ora, é precisamente este tipo de redução do seu trabalho que várias publicações feitas por seus alunos, ou por pessoas que o reivindicaram, foram capazes de conduzir. Este erro fundamental baseou-se principalmente em um mal-entendido das tabelas do nono acorde para as diferentes partes do corpo, com a ideia de que Delsarte propôs gestos codificados para essa ou aquela emoção. ${ }^{8} \mathrm{~A}$ má interpretação deste tipo de representação vem, em grande parte, da ignorância de seu substrato metafísico e, mais particularmente, teológico.

6 Expressão pelo gesto. (Nota de tradução).

7 Esthétique appliquée, cours de F. Delsarte. Exposition en neuf leçons de l'art de l'orateur, du peintre et du musicien. Offert à M. Delsarte par son élève Alphonse Pages (Delsarte Collection, Hill Memorial Library, Louisiana State University, Baton Rouge, Louisiane, États-Unis d'Amérique, box 12c, folder 40), cours théorique $\mathrm{n}^{\circ} 1$.

8 Joseph Fahey, em seu artigo sobre delsartismo, escreveu que "a essência da [avaliação negativa do sistema Delsarte] é devido ao poder das imagens que são mais fortes que as palavras. As representações gráficas dos sistemas derivados de Delsarte muitas vezes ofuscam os aspectos mais sutis e complexos de seus escritos" ("Much of this negative assessment is due to the power of images over words. Pictorial representations of systems derived from Delsarte frequently overshadow the more subtle and complex aspects of his writing. As representações pictóricas de sistemas derivados de Delsarte frequentemente ofuscam os aspectos mais sutis e complexos de sua escrita"). As representações pictóricas de sistemas derivados de Delsarte frequentemente ofuscam os mais sutis e complexos de seus escritos. "(Joseph Fahey, in. Th. Leabhart (ed.), Essays on François Delsarte, Mime Journal 2004/2005, Claremont, CA Pomona College Theatre Department for Claremont Colleges, 2005, p. 45). 
O nono acorde baseia-se na definição teológica da Trindade (mais precisamente na versão dada por Tomás de Aquino, principal referência de Delsarte), levando à noção de circumincession $^{9}$. No pensamento de Tomás de Aquino, a relação está no centro da Trindade: o Pai não é apenas ele mesmo, mas também a relação com o Filho e a relação com o Espírito Santo - assim é, para cada uma das duas outras pessoas, trinitárias. Desta forma, a unidade das três pessoas se manifesta em nove termos. $O$ nono acorde é, para Delsarte, a tradução plástica da circumincession. A versão deste acorde aplicado às cores possibilita a inserção de uma maneira simples. Aqui está a tabela que podemos tirar dos cursos oferecidos por Delsarte (com as limitações da ferramenta de computador usada aqui):

Figura 2: Tabela do nono acorde de cores de acordo com os cursos de 1859

(7 curso teórico)

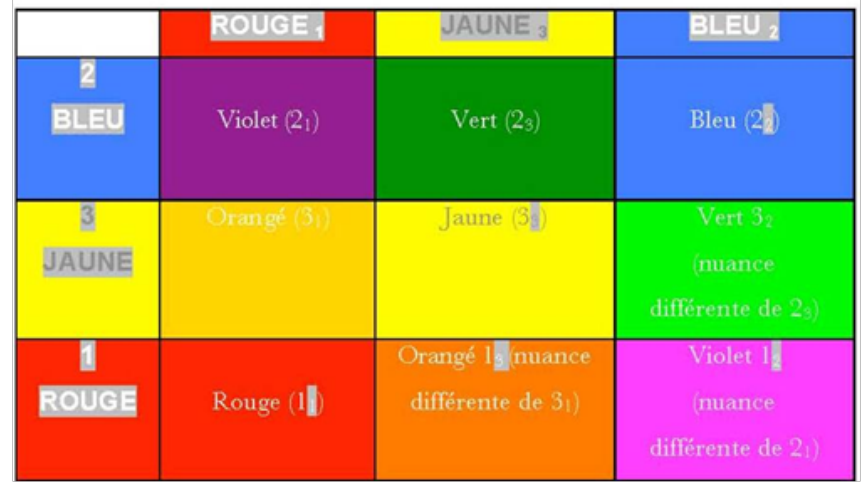

Nós temos as três cores primárias como critérios horizontais e verticais desta tabela de entrada dupla, em seguida, na diagonal, indo

9 Circumincession: palavra que vem da teologia de São Tomás de Aquino e que fala das relações dentro da Trindade (o Pai está em relação ao Filho e ao Espírito Santo; o Filho está em relação ao Pai e ao Espírito Santo; o Espírito Santo está em relação ao Pai e ao Filho, o que significa que para as 3 Pessoas iniciais : Pai, Filho e Espírito Santo, devemos adicionar os 6 tipos de relações, o que somara 9 termos). (Nota de tradução). de vermelho para azul. As outras seis caixas são as combinações das três cores primárias, onde uma ou outra tem a predominância. Isso forma a paleta básica de cores. Para cada uma das cores primárias (ou elementos que podem ocupar seu lugar de acordo com o objeto estudado), Delsarte atribuiu uma qualidade particular: excêntrica (dinâmica dirigida do interior para o exterior) para vermelho; concêntrica (dinâmica oposta, dirigida do exterior para dentro) azul; neutro (balanço das duas anteriores) para o amarelo. Essa qualidade é derivada diretamente da definição tomasiana de Trindade (o Pai é visto como uma potência fecunda, excêntrica por excelência, etc.) e fornece uma informação do tipo energética sobre o que está posicionado nesse ou naquele caso. Ao mesmo tempo, as indicações de tipo emocional indicadas na tabela da mão ("exasperação", "luta”, "abandono", por exemplo) nos lembram que as atitudes das diferentes partes do corpo que são então mencionadas, provêm diretamente das observações de Delsarte, que encontram aqui uma estrutura de organização e de apresentação sintética e dinâmica: "Este simples meio [permite-lhe] inscrever os inúmeros fatos que ele perseguiu, e que chegam a milhões, [sem estar perdido] nestes milhões de fatos" 10 .

O nono acorde, estruturado de acordo com regras precisas, é ao mesmo tempo flexível o suficiente para abraçar as variações infinitas das "motivações internas", as emoções. Em uma leitura errônea desta tabela, omitimos sua dinâmica interna ligada ao seu aspecto sintético, que não é normativo. Esta tabela é, acima de tudo, uma ferramenta com um processo de subdivisões sucessivas: cada elemento, resul-

10 Cours de M. Delsarte aux Sociétés savantes, (Delsarte Collection, op. cit., box 12 b, folder 54), cours $n^{\circ} 6$. 
tante da passagem de três gêneros para nove espécies, pode, por sua vez, ser dividido de acordo com a mesma lógica ternária de acordo com um processo sem fim (por sua vez, as espécies podem ser combinadas com os três gêneros, isto é, cada um dividido por três, etc.). Esse processo de multiplicação permite que ele aperfeiçoe sua análise para detalhar os fenômenos expressivos, pressionando a descrição dos fenômenos dentro do limite do aplicável. ${ }^{11}$ Além disso, cada um desses elementos, relacionados a uma parte específica do corpo, deve ser combinado com os das outras partes do corpo, toda expressão é feita da participação de diferentes elementos corporais, ou mesmo de todo o corpo. O conjunto dessas combinações é, então, difícil de numerar. A abordagem dada abre, assim, ao infinito o campo das possibilidades de análise e do trabalho da expressão humana. Delsarte, portanto, contemplou uma obra artística que, longe de ser rígida, tende a uma paleta ilimitada de expressões. Com o nono acorde, ele tem uma grade de leitura do mundo e, em particular, dos fenômenos expressivos, que tendem por seu número para o infinito, e que ele afirma trazer de volta para nove. Não para reduzir tudo a nove, mas para poder trabalhar tudo a partir de nove elementos. Podemos ver a ferramenta do nono acorde como uma tentativa de ultrapassar os limites impostos pelos meios técnicos de representação do corpo em movimento antes da invenção do cinematógrafo: ele propõe de se treinar para encadear as diferentes

11 Delsarte mencionou milhares, ou mesmo milhões, de atitudes possíveis para tal ou tal parte do corpo. Na verdade, ele listou 28.149 "sinais inflexíveis. Essas 28.149 formas combinadas entre elas que produzirão milhões de modificações, que certamente estão na natureza". (Fusion des signes, in Fonds Serge Bouts, Paris carton jaune, dossier 13, document $6)$. atitudes indicadas "de todas maneiras"12 (ou seja, em qualquer ordem), como apontou Alfred Giraudet, um aluno direto de Delsarte. E, desta forma, experimentar diferentes atitudes, posições e níveis de possíveis tensões musculares desta ou daquela parte do corpo. Sinais inflexíveis.

Sem o seu substrato metafísico, essa tabela é, portanto, uma ferramenta rígida e normativa, enquanto que ela é essencialmente dinâmica. Nosso trabalho é o primeiro a conectar a teologia de Thomas de Aquino e as ferramentas teóricas de Delsarte, o que nos permite entendê-las bem.

\section{Uma pedagogia que procura manter as realidades expressivas humanas}

Os nono acordes para as diferentes partes do corpo foram, portanto, apoios pedagógicos para um ensino corporal expressivo que permitem trabalhar, de maneira precisa e fina, os diferentes elementos que constituem a expressão gestual. A realidade viva e dinâmica do nono acorde é o coração da pedagogia artística de Delsarte.Esta pedagogia centra-se numa observação constante das realidades expressivas, tendo um objetivo claramente definido: a espiritualização do artista a fim de ajudar a espiritualização do espectador. Praticamente, visa tornar o aluno autônomo em relação ao professor, propondo-lhe uma série de regras a serem verificadas por si mesmo, o que lhe permite não depender da subjetividade do professor, mas poder justificar suas escolhas de acordo com as leis reforçadas pela observa-

12 Alfred Giraudet, Mimique, Physionomie et Gestes. Méthode Pratique D'après le système de François Del Sarte pour servir à l'expression des sentiments, Paris, Ancienne Maison Quantin / Librairies-Imprimeries Réunies, 1895, p. 119. 
ção de si e dos outros.

A trajetória de Delsarte, que descobriu através de suas próprias observações, a essência do que ele transmitiu, - e que sofreu a arbitrariedade de professores no Conservatório e depois se converte ao cristianismo - é o modelo desta abordagem pedagógica. Esta jornada encontra um eco nas experiências de Agostinho de Hipona, relacionadas em particular nas Confissões, às quais Delsarte se refere explicitamente: "Bem, o espetáculo que eu quero que você contemple está no interior. (...) Desça em si mesmo: Santo Agostinho"13. A ideia principal é que, ao conhecermos a nós mesmos, seria possível descobrir que somos habitados pelo divino. Despertar a consciência do ser humano como portadora do divino é o objetivo que Delsarte estabelece para o ato artístico. $\mathrm{O}$ artista, segundo ele, deve ser o meio desse despertar, e para isso ele deve ser despertado.

Ao mesmo tempo, Delsarte se distinguiu da tradição agostiniana, que considerava que a imagem do divino dizia respeito à alma - o corpo sendo concebido como um recipiente ${ }^{14}$. Delsarte escreve:

É para esta misteriosa exploração de si mesmo, é para esta jornada através de vocês mesmos que eu convido você. Até as profundezas do seu organis$\mathrm{mo}^{15}$ quero fazê-lo descer. Eu guiarei seus passos, e lá, do próprio seio das trevas, surgirão diante dos seus olhos as luzes transluminosas da Jerusalém que carregamos dentro de nós ${ }^{16}$.

13 L'homme objet d'étude (Delsarte Collection, op. cit., box 1a, folder OS 36b, document 18), p. 1.

14 Um recipiente que contém a alma. (Nota de tradução).

15 As palavras: "natureza" e "ser" foram riscadas do manuscrito. (Nota de tradução

16 Idem.
Delsarte, depois de ter pensado em palavras mais abstratas e filosóficas, volta, com o termo "organismo", ao que mais se aproxima de sua experiência pessoal como artista, mas também a uma experiência mística associada à sua conversão, na qual ele afirma ter visto que "o corpo humano é o alfabeto (...), a enciclopédia do mundo ... e o Diamante da criação"17 - em outras palavras, o corpo seria o objeto a ser estudado preferencialmente para qualquer compreensão dos fenômenos expressivos. Este estudo diz respeito tanto ao corpo em sua organização quanto ao seu funcionamento, daí as formações que Delsarte seguiu em anatomia e fisiologia. Pela ideia de "enciclopédia do mundo", é preciso entender o corpo como um reflexo do divino manifestado em todo o universo. Isso permite esclarecer a perspectiva geral de Delsarteque,segundo ele, seria: "restaurar à metafísica as bases físicas sem as quais ela é apenas uma sombra vã"18.

O substrato espiritualista de seus ensinamentos não os impede de ter um "aparente secularismo absoluto"19. Ted Shawn, ardente defensor do trabalho do artista francês e o primeiro coreógrafo moderno nos Estados Unidos, afirma, de acordo com sua experiência: "Se aderimos ou não à metafísica de Delsarte, seu sistema é utilizável" (SHAWN, 2005, p. 63). A capacidade de Delsarte de traduzir dados metafísicos em termos concretos está diretamente ligada à importância central do corpo em seu trabalho, e é dentro do quadro da

17 Delsarte Collection, op. cit., box 1, folder 36b/items 1-7, document 7 .

18 Notre méthode (The papers of the Mackaye Family, op. cit., box 22 ML5 (22), folder 1), document 4.

19 “L'apparente laicità assoluta del metodo (...)" (Roberto Tessari, "L'attore in Delsarte", in Elena Randi, François Delsarte : le leggi del teatro. Il pensiero scenico del precursore della danza moderna, Roma, Bulzoni editore, 1993, p. 83). 
análise e do trabalho do corpo que se chega à melhor compreensão da articulação entre os aspectos teóricos e práticos de seus ensinamentos. Esta importância do corpo humano é encontrada particularmente em dois níveis: na análise do movimento (do corpo em movimento) e na concepção geral do ser humano, não dualista.

\section{no cruzamento entre observações e a estrutura teórica de Delsarte}

A análise do movimento feita por Delsarte é construída em torno de três elementos centrais: a noção de oposição, a importância da parte superior do busto (região do tórax) e o papel do peso. Esses três elementos se referem às diferentes fontes do sistema expressivo.

A noção de oposições é considerada como fonte de equilíbrio estático e dinâmico, permitindo assim o movimento: Delsarte fala da lei "das oposições na dinâmica"20. Observações sobre a marcha, ilustradas, por exemplo, no final do século XIX pelos cronofotográficos de Étienne-Jules Marey, mostram que esta é feita de acordo com um movimento de oposição contralateral: se a perna direita está avançada, é que o ombro esquerdo também está (enquanto a perna esquerda e o ombro direito estão para trás). Essa noção de oposição também foi identificada por Delsarte na estatuária antiga grega, que ele estudou por muitos anos no Louvre e em que ele afirma ter descoberto as regras de equilíbrio do corpo e as leis da expressão humana pelo gesto e pelo movimento. A estatuária grega introduziu a posição

20 Notebook of Mackaye while studying with Delsarte (Delsarte Collection, op. cit., range 35), p. 91. em contraposto, "que se caracteriza por esse deslocamento lateral do quadril causado pelo apoio do equilíbrio em um único pé e o deslocamento lateral da cabeça gerado pela torção do busto. (...) Uma combinação de movimento e repouso, equilíbrio e assimetria: uma dança de oposições" (BARBA; SAVARESE, 2008, p. 170)que permite dar uma sensação de movimento às figuras fixadas no mármore.

Finalmente, do ponto de vista teórico, a noção de oposição é comum à teologia trinitária e ao esoterismo. Assim, a noção de oposições complementares ou, segundo as palavras de Antoine Faivre, "de dualidades" ou "antagonismos estruturais" 21 tendo uma dinâmica de unidade (oposições alto/baixo, espiritual/material, homem/mulher, etc.) está "presente em todo o hermetismo"22. As oposições são consideradas como a principal estrutura do mundo, "tudo [...] participando em um conjunto de forças opostas em tensão viva"23. Delsarte leu esses antagonismos estruturais como subjacentes a toda revelação cristã e falava então de "antinomias"24. Teologicamente, o princípio da oposição é o cerne da definição tomasiana da Trindade: ele está na origem da individuação e, portanto, na relação entre as três pessoas trinitárias. $\mathrm{Na}$ verdade, na medida em que as relações definem as pessoas divinas no Aquino, elasestão cara a cara, isto é, relações de oposição. ${ }^{25}$

21 Antoine Faivre, Accès de l'ésotérisme occidental, Paris, Gallimard, 1996, I, p. 44.

22 Idem.

23 Ibid., I, p. 45.

24 "Antinomias. O que! Essa reversão!!! Os incriados nascerão e sofrerão. O imortal receberá a morte. O verbo se tornará carne (...)". (Les folies de la sagesse divine, Delsarte Collection, box 1a, Folder OS 36b/item 6, document 1).

25 Thomas d'Aquin, Somme théologique, la, q. XL, a. 3, Paris, Cerf, 1984, vol. 1, p. 435-437. 
A importância central do torso também está nocruzamento das observações e teorias de Delsarte sobre o simbolismo do corpo humano. Se tomarmos o exemplo da caminhada, a análise delsartiana mostra que ela não tem sua origem nem nas pernas nem na pélvis, mas na parte superior do tronco. Uma análise atual indica que:

Quando um passo é uma sucessão de quedas para a frente [o que é o caso mais comum da caminhada], a linha que representa o eixo do corpo - um eixo que passa da orelha ao tornozelo - está permanentemente inclinado para a frente em relação a uma linha de prumo vertical. As pernas devem recuperar rapidamente o equilíbrio e amortecer um acréscimo de peso devido à queda. ${ }^{26}$

Comumente, Delsarte considerava que "todo movimento vem do impulso do coração"27, um coração que deve ser entendido simultaneamente como amor e coração físico. Em outras palavras, o peito é visto como o principal centro dinâmico do corpo: é a partir dele que o movimento expressivo prossegue. No simbolismo corpóreo, que ele desenvolveu a partir de uma base trinitária, ele viu o topo do tronco, mais especificamente a região do coração e do plexo solar, como a parte mais espiritual e emocional do corpo, em oposição às partes mais vitais (a pélvis, as pernas), ou mais intelectual (a cabeça).

Este impulso do coração no movimento está associado à importância do peso, o que está

26 Claire Hegen, Yves Marc, "La marche et l'acteur", em Odette Aslan (ed.), Le corps en jeu, op. cit., p. 361. Estes autores também apresentam outros tipos de etapas: por uma sucessão de quedas na vertical, por tração (o corpo reboca o corpo que permanece vertical ou inclina-se para trás), por propulsão (tronco vertical movido para a frente pela perna traseira).

27 Carnet de Delsarte (Delsarte Collection, op. cit., box 2c, folder 88). sempre relacionado às observações e a sua estrutura teórica. Em particular, Delsarte faz uma série de associações baseadas em noções bíblicas (medida, número e peso ${ }^{28}$ ) e de análise racional de fenômenos no mundo trinitário (tempo, espaço, movimento ${ }^{29}$ ), o que o leva a afirmar que "o peso engendra movimento"30! Esta ligação de peso e movimento é essencial porque induz uma noção de qualidade do movimento: não feita em força, por tensões musculares, mas pela gestão fluida do peso em uma série de equilíbrios e desequilíbrios. Essa noção, juntamente com a importância do impulso no torso, é fundamental na história do desenvolvimento da dança moderna

\section{do ser humano e dos processos emocionais tem ecos atuais}

A noção de qualidade do movimento no trabalho de Delsarte também é ditada por uma idéia diretriz, simples e central: a expressão especialmente pelo movimento - não deve ser ditada pela preocupação com o virtuosismo, mas para buscar refletir uma realidade interna. Essa dinâmica expressiva é baseada em uma concepção não dualista do ser humano.

A importância do corpo coloca Delsarte em uma posição singular em relação ao cristianismo de seu tempo, durante o qual "o cristão é levado a desprezar seu corpo" ${ }^{31}$. Mas este

28 "Mais tu as tout réglé avec mesure, nombre et poids", (Sg 11, 20, in La Bible de Jérusalem, Paris, Cerf, 1994, p. 975). "Mas, você resolveu tudo com medida, número e peso".

29 Notebook of Mackaye while studying with Delsarte (Delsarte Collection, op. cit.,, box 2c, folder 2), p. 115.

30 Cours de M. Delsarte aux Sociétés savantes $n^{\circ} 5$, in Alain Porte, François Delsarte, ..., op. cit., p. 109.

31 Gérard Cholvy, Yves-Marie Hilaire, Histoire religieuse de la 
lugar do corpo deve ser entendido no âmbito de uma visão unificada do ser humano, na qual a alma (ou princípio espiritual) e o corpo estão intimamente associados. As experiências iniciais de Delsarte como artista, observando constantemente correlações entre realidades emocionais e processos expressivos, encontraram dois tipos de suporte teórico. Por um lado, Delsarte conseguiu fazer uma leitura correta da antropologia de Thomas de Aquino, longe das deformações do tomismo dominante em seu tempo para a interpretação dos textos de Aquino.

Isto foi, sem dúvida, devido à sua intuição, mas também a um treinamento sólido com os jesuítas (o Abade de Ravignan em particular) e dominicanos (ele foi um dos primeiros membros da Ordem Terrestre Dominicana reestabelecida na França pelo Lacordaire em 1844), e uma leitura direta do texto original. Ele citava ou reformulava de forma sistemática, quando falou de sua concepção do ser humano, uma frase de Tomás de Aquino: "A alma, considerada de acordo com sua essência, é a forma do corpo"32. O Aquino era parte da visão aristotélica do homem, em que a forma é o princípio não material da existência das coisas, permitindo que cada tipo de coisa seja o gênero de coisa que ela é. A alma, como forma do corpo, é então substancialmente unida a ela. Por conseguinte, esta concepção énão dualista e insiste na unidade complexa do composto humano unindo dois princípios opostos: a alma, a causa formal, e o corpo, a causa material. Isto significa insistir na unidade fundamental do ser humano em todas as suas dimensões.

Por outro lado, Delsarte baseia-se na noção

France contemporaine. 1800-1880, Paris, Privat, 2000, p. 60.

32 Thomas d'Aquin, Somme théologique, la, Q. 76, a.1, sol. 4, op. cit., vol. 1, p. 665. de correspondências universais usada em círculos esotéricos ("O que está embaixo, é como o que está em cima") ${ }^{33}$, e que ele reformula para aplicá-la ao ser humano, uma reformulação que propomos chamar de "lei das correspondências humanas" a qual é a seguinte: "a cada função espiritual responde uma função do corpo; a cada grande função do corpo responde um ato espiritual"34. Esta dinâmica é diretamente aquela que está em função na busca de uma expressão que sejaum reflexo da alma, e na ideia de que o ato artístico pode atuar sobre a interioridade do espectador. Ela encontrou muitos ecos, tanto no teatro contemporâneo como na dança moderna. Assim, a ideia de que o corpo em movimento diria alguma coisa sobre a alma tornou-se não só "um axioma da dança moderna americana" 35 , mas da dança moderna como um todo, em ambos os lados do Atlântico.

Delsarte não só usa seus referentes teológicos e esotéricos, mas também lhes dá uma extensão sem precedentes. De fato, a associação deste quadro teórico com uma prática artística é inovadora em relação às referências utilizadas e deu, pela primeira vez ao nosso conhecimento, uma extensão corpórea e expressiva aos dados antropológicos baseados em filosofia, teologia e pensamento esotérico. Por outro lado, as conclusões de sua análise de processos emocionais baseados na unidade fundamental do ser humano, encontram múltiplos ecos na pesquisa atual na fisiologia da ação e da emoção. As obras de Alain Berthoz

33 La Table d'Émeraude et sa tradition alchimique (atribuído ao lendário Hermes Trismegistus), apresentado por Didier Kahn, Paris, Les Belles Lettres, 2002, p. 43.

34 Delsarte Collection, op. cit., box 1, folder 36a/items 9-14, document 3.

35 Nancy Lee Chalfa Ruyter, in Ted Shawn, Chaque petit mouvement..., op. cit., p. 18. 
e Antonio Damasio, em particular, enfatizam a associação íntima de estímulos internos (emoções) e suas manifestações (expressões). Eles, portanto, posicionam-se em uma perspectiva totalmente oposta ao dualismo da modernidade ocidental, que foi precisamente o caso de Delsarte em seu tempo, mesmo que as ferramentas utilizadas por cada um deles sejam diferentes.

\section{A abordagem simbólica de Delsarte para o corpo: uma maneira de iluminar os laços entre arte e espiritualidade}

Segundo Delsarte, a importância do torso em cada movimento e, especialmente, em qualquer movimento expressivo, como o apresentamos acima, está incluída em uma abordagem simbólica global para o corpo. Desdobra-se em duas etapas. Delsarte apreendeu o corpo por uma série de subdivisões ternárias, tendo cada uma delas, uma dimensão de energia expressiva e direcional. A mais abrangente dessas divisões, que ele chamou de divisão essencial, individualiza pélvis (vital, movimento do interior para o exterior, frente, excêntrica), cabeça (intelectual, movimento do exterior para o interior, concêntrica) e tórax (espiritual e emocional, agindo como equilíbrio entre a a pélvis e a cabeça, contendo o coração, os pulmões e o plexo solar): diz respeito aos focos de atividade orgânica. Esta divisão pode incluir os membros como extensões. A segunda grande divisão é chamada por Delsarte de divisão estética: é de alguma forma a projeção expressiva da divisão essencial. Possui uma série de subdivisões, que esclarecem a dinâmica expressiva do corpo. Aqui estão as possíveis representações dessas duas abor- dagens do corpo:

Figura 4: Divisão essencial do corpo (o segundo desenho integra os membros)

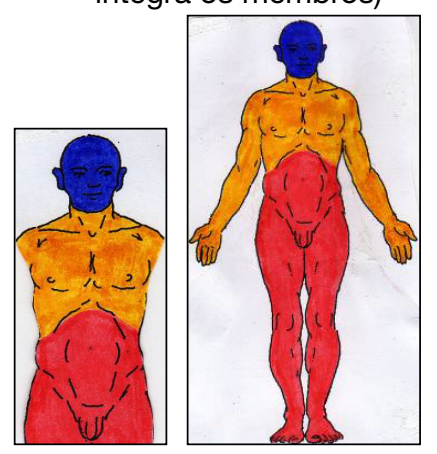

Figura 5: Divisão estética do corpo e sua primeira subdivisão
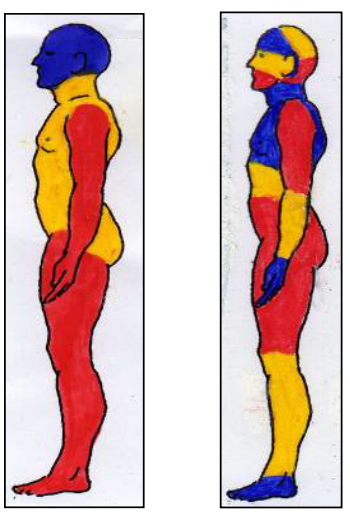

Nessas representações que fizemos a partir das informações nos documentos de arquivo, a cor vermelha caracteriza o que é vital; o azul, o que é intelectivo; o amarelo, o que é espiritual e emocional. É este último ponto que desejamos concluir aqui. Vemos que as partes do corpo especificamente relacionados com as dinâmicas espirituais e emocionais são o torso em sua totalidade (fonte do movimento) - divisão estética - e, especificamente, a parte superior do tronco (divisão essencial) ou a região que Delsarte chamava de epigástrica (área do estômago), que é o plexo solar (primeira subdivisão da divisão essencial). Estas abordagens simbólicas do corpo são, de certa forma, a síntese das observações de Delsarte e seu quadro teórico metafísico e espiritual. Elas enfatizam as principais dinâmicas de seus ensinamentos tanto práticos como teóricos, 
em particular esta: segundo ele, todo trabalho expressivo orientado para o desenvolvimento da dimensão emocional do ser humano está intimamente ligado a um trabalho espiritual desenvolvido fora de qualquer quadro religioso possível (porém, sem contradizê-lo). E, o trabalho do corpo e do movimento, de acordo como são propostos, promovendo o papel do torso, agiria diretamente no plano psicoespiritual, favorizando a espiritualização do artista e, em consequência, de sua obra.

Esta abordagem parece-nos ainda capaz de atrair o interesse e merecer a experimentação. Nos parece que este é o caso do conjunto dos ensinamentos práticos de Delsarte.

\section{A atualidade potencial dos ensinamentos expressivos de Delsarte}

Nosso trabalho examina minuciosamente os elementos do debate sobre a realidade e o conteúdo dos ensinamentos corporais de Delsarte. Isso nos permite afirmar que as concepções precisas do corpo, do ser humano como um todo e do movimento, estão associadas na sua obra a um trabalho minucioso em coerência com o funcionamento geral de seus ensinamentos: sempre associando teoria e prática, porque, de acordo com ele, a teoria é "interessante como um meio de encurtar o caminho, mas é necessário chegar à prática" ${ }^{36}$. Apresentamos elementos que permitem conhecer melhor o treinamento corporal elaborado por Delsarte, concebido no âmbito de uma pedagogia do canto e da fala articulada, orientada basicamente para o gesto e o movimento.

Um conhecimento preciso dos ensinamen-

36 Cours de M. Delsarte aux Sociétés savantes, op. cit., $\mathrm{n}^{\circ} 10$. tos de Delsarte, tendo em conta a sua complexidade e sua delicadeza, permite considerá-los como sempre viáveis e relevantes desde a perspectiva da formação de artistas intérpretes do espetáculo vivo. As concepções delsartianas do ato artístico intimamente relacionado com as realidades emocionais observadas, a insistência de Delsarte sobre o que chamamos de comunicação não-verbal e sobre o trabaIho corporal, são sempre de interesse para o trabalho do bailarino ou do ator. Assim, houve uma reavaliação positiva desses ensinamentos no mundo do teatro americano desde a década de 1960, do ponto de vista histórico, mas também para uma prática contemporânea. ${ }^{37}$ Uma série de trabalhos desenvolvem a ideia de que teria havido um desvio dos ensinamentos originais ${ }^{38}$ e que esses desvios desvalorizaram o trabalho de Delsarte na América. Nesse sentido, a pesquisa em profundidade que realizamos nos permite compreender melhor a dinâmica do trabalho de Delsarte e pode ser de interesse direto para os círculos de treinamento de atores. A pedagogia de Delsarte é estranha a qualquer noção de codificação e se concentra na observação de realidades expressivas e em um trabalho corporal rigoroso

37 Cf. os seguintes artigos : Kirby E. T., "The Delsarte Method: 3 Frontiers of Actor Training", The Drama Review, volume 16, number 1 (T.53), mars 1972, p. 64-67; Gautam Dasgupta, "Commedia Delsarte", Performing Arts journal, n 45, Baltimore, Maryland, USA, septembre 1993, vol. XV, n 3, p. 95-102; Joseph Fahey, "Quiet Victory: The Professional Identity American Women Forged Through Delsartism", Thomas Leabhart (dir.), Essays on François Delsarte, Mime Journal 2004/2005, Claremont, Californie, Pomona College Theatre Department for Claremont Colleges, 2005, p. 43-83.

$38 \mathrm{Cf}$. as seguintes teses: Claude L. Shaver, The Delsarte System of Expression As Seen Through the Notes of Steele Mackaye, Ph. D. Dissertation, University of Winsconsin) ; Leslie Carol Schreiber , Movement Training for the Actor : Laying the Foundation in Movement Principles, Ph.D. dissertation, University of Minnesota ; Janis Dawn Clarke, The Influence..., op. cit. ; David Tabish, Kinesthetic Engagement Technique: Theories and Practices for Training the Actor, Ph.D. dissertation, University of Pittsburgh, 1995. 
de desaprendizagem e de reaprendizagem. Ele visa a autonomia do aprendiz e sua liberdade criativa.

O trabalho de preparação do corpo, em particular, mantém seu interesse no que Eugenio Barba chama de trabalho pré-expressivo. O ponto de partida deste trabalho, que Delsarte chamou de decomposição - o que corresponde em geral ao relaxamento, mas com ênfase no relaxamento dos vários segmentos do corpo a partir das articulações - foi sem dúvida uma inovação no Ocidente com relação ao trabalho corporal para fins expressivos. No processo de decomposição, o uso do peso desempenha um papel central, como em tudo o que diz respeito ao corpo em movimento no trabalho de Delsarte. Retornar a este ensinamento fundador é uma oportunidade para enriquecer as práticas atuais, que podem ter sido indiretamente inspiradas por ela, ao mesmo tempo em que se afastam de alguns dos processos básicos desenvolvidos por Delsarte (muitas vezes se afirma que se relaxa o pescoço fazendo rotações, em vez de deixar que a cabeça tombe com seu próprio peso).

Além disso, a insistência de Delsarte no papel motor e emocional do torso superior e na qualidade do movimento associado à tradução de um "movimento interno", permanecem altamente relevantes para uma prática de dança ou para um olhar crítico nas criações coreográficas atuais, que tendem, às vezes, a abordar as práticas esportivas (como afirmou o coreógrafo Gilles Jobin) e, nas quais, a pélvis tornou-se a força motriz, em detrimento do topo do busto (que é o caso, por exemplo, na técnica derivada de Merce Cunningham).

Finalmente, de uma maneira muito mais ampla, o fenômeno americano de Delsartemania, no final do século XIX, mostrou que uma prática corporal e vocal baseada nos ensinamentos de Delsarte poderia alcançar uma ampla audiência além dos círculos artísticos. O trabalho de Delsarte, às vezes referido como "yoga ocidental"39, é, ao mesmo tempo, exigente porque requer atenção e duração, e é de fácil acesso, porque não visa a proeza técnica e leva em consideração as realidades da pessoa. É, em muitos aspectos, semelhante a algumas das técnicas asiáticas, como a yoga ou as artes marciais, com a diferença de que não tem um objetivo marcial nem meditativo, mesmo que ele tenha tido como base a ideia de que todo o trabalho do corpo tem implicações internas. Assim, o trabalho do equilíbrio corporal, central para a prática delsartiana, teria um efeito direto sobre o equilíbrio psíquico - poderíamos então falar de equilíbrio psicomotor. Este trabalho também tem a peculiaridade, em relação às práticas que acabamos de mencionar, de ter seus referentes na cultura ocidental. Longe da ideia de ginástica (no sentido de uma prática formal e mecânica do corpo), o treinamento físico incluído no método de Delsarte, potencialmente continua a ser uma oferta no mercado de trabalho do corpo e de desenvolvimento pessoal, em plena expansão nas sociedades ocidentais.

\section{Os ensinamentos expressivos de Delsarte anunciam a educação somática}

Profundamente, o treinamento proposto pelo método de Delsarte é mais do que uma obra puramente corporal: ele associa intimamente a consciência do que acontece em si mesmo durante os fenômenos expressivos e,

39 Cf. anuncio publicitário para o trabalho de Hellès-Abilea, in Le Figaro littéraire du 06/01/1962, p. 12. 
especialmente durante os movimentos, o gesto sendo visto como a tradução de um movimento íntimo e psíquico. Seria necessário tomar consciência dessa relação entre movimento e sua origem. É por isso que escolhemos falar de uma abordagem "somática-expressiva" com relação a Delsarte. Colocar todos os ensinamentos delsartianos centrados no gesto sob o termo "somático expressivo", ao invés de "corpóreo expressivo", tem um significado histórico real: colocar Delsarte como um dos inspiradores do que é hoje chamado educação somática. ${ }^{40}$

Não podemos deixar de lembrar nesta perspectiva, que os ensinamentos de Delsarte faziam parte da formação daquele que é considerado o iniciador da educação somática no século XX, Frederick Matthias Alexander, ou o de outros que seguiram essa abordagem, como Elsa Gindler. E ainda, a pessoa que introduziu o termo somático, Thomas Hanna, não relaciona Delsarte na gênese dessa abordagem, mesmo que o trabalho de Delsarte seja mencionado no campo da educação somática como participante na renovação de estudos culturais (cultural studies) em uma dinâmica multidisciplinar. ${ }^{41}$

Ao optar por aplicar ao trabalho de Delsarte o termo somático, propomos ver precisamente em seus trabalhos um dos elementos da gênese da educação somática que se desenvolveu no século $X X$. Por conseguinte, é necessário explorar em profundidade os ensinamentos delsartianos e mostrar como eles podem le-

40 Cf. Franck Waille, La méthode somatique expressive de François Delsarte. Histoire, esthétique, anthropologie: de la neurophysiologie à la métaphysique, Montpellier, L'Entretemps, 2016.

41 Cf. Martha Eddy, "A brief history of somatic practices and dance: historical development of the field of somatic education and its relationship to dance", Journal of Dance \& Somatic Practices, vol. I, no 12009, 2009, p. 5. var as dinâmicas da educação somática, em termos da concepção integrada das diferentes dimensões da pessoa e do que poderíamos chamar de pedagogia da observação, da atenção e da consciência do que está acontecendo em si durante o movimento. Sua abordagem enfatiza a experiência e a consciência do que está acontecendo em si mesmo. Mais especificamente, ela insiste na consciência dos fenômenos proprioceptivos, assim como considera a relação gravitacional e a orientação da atenção como elementos fundamentais na condução do movimento.

Outra opção é usar a expressão "trabalho somático expressivo" (ou "método somático expressivo"). Este termo é incomum no campo da educação somática. No caso de Delsarte, lembramo-nos que todo o trabalho preparatório que ele propõe e que se baseia na consciência dos processos naturais tem precisamente e, in fine, um objetivo expressivo: nutrir as habilidades criativas do indivíduo, as ferramentas de composição do artista. Se o seu trabalho é potencialmente aberto a qualquer um, foi projetado preferencialmente para os artistas, e a dimensão expressiva em seu trabalho é o que provavelmente caracteriza a capacidade de integrar as diferentes dimensões da pessoa. Esta abordagem expressiva não está distante dos objetivos de algumas das práticas no campo da educação somática, em particular o trabalho de Imgard Bartenieff (colaboradora de Rudolf Laban), Análise Funcional do Corpo no Movimento Dançado (AFCMD) iniciado por Hubert Godard e Odile Rouquet, ou Body-Mind Centering ${ }^{\circledR}(\mathrm{BMC})$ iniciado por Bonnie Bainbridge-Cohen. Se a expressão "trabalho somático expressivo" é incomum, refere-se, no entanto, a perspectivas que já fazem parte da educação somática contemporânea em que 
o funcional e o expressivo estão intimamente associados.

Em geral, estamos convencidos de que as pesquisas de Delsarte estão atrás de nós - pois permitiram o surgimento de novas dinâmicas para as artes cênicas e o surgimento de práticas de educação somática - mas estão também adiante de nós: já que muitos dos seus conteúdos ainda estão longe de ser totalmente integrados, e há uma riqueza real neles que pode permitir explorações fascinantes para melhor descobrir a maravilhosa organização expressiva que nos constitui.

\section{Referências}

ARNAUD, Angélique (1882). François del Sarte, ses découvertes en esthétique, sa science, sa méthode, précédé de détails sur sa vie, sa famille, ses relations, son caractère, Paris, Ch. Delagrave.

DELAUMOSNE, Abbé (1874). Pratique de l'art oratoire de Delsarte, Paris, Joseph Albanel.

DELSARTE, François (1865). « Esthétique appliquée - Des sources de l'art », Conférences de l'Association philotechnique, Victor Masson et fils, Paris, p. 89-139.

DELSARTE, François (1882). All the Literary Remains of François Delsarte, in Delsarte System of Oratory, New York, Edgar S. Werner.

DELSARTE, François (2015). "Conseil à mes élèves », in Waille, Damour, 2015, p. 296-298.
DELSARTE, François (2016a). « Geste de rejet / Geste de l'ordre et de la réitération », in Waille (2016), p. 476-477.

DELSARTE, François(2016b). « Textes inédits de Delsarte sur le corps ", in Waille, 2016, p. 479-484.

GIRAUDET, Alfred (1884/1885). « The Delsarte System », Werner's Voice Magazine VII, no 1, dec./jan., p. 9-10.

GIRAUDET, Alfred (1893). « Trueness in Singing ", in Delsarte System of Oratory, New York, Werner, p. 569-573.

GIRAUDET, Alfred (1895). Mimique, Physionomie et Gestes. Méthode Pratique D'après le système de François Del Sarte pour servir à l'expression des sentiments, Paris, Ancienne Maison Quantin/Librairies-Imprimeries Réunies.

GODARD, Hubert (1990). «À propos des théories sur le mouvement ", Marsyas, vol. 16, p. 19-23.

HAMEL, Thomas-Étienne (1906). Cours d'éloquence parlée d'après Delsarte, Québec, Imprimerie de la compagnie de l'Événement.

HARBONNIER-TOPIN, Nicole, \& FERRI, Catherine (2011). Pre-movement, an essential moment for the dancer. Communication presented at the Dance Kinesiology Teachers Group Conference (24-26 june 2011), Brockport, New York (http://www.brockport.edu/dance/docs/ DKTGannouncement.pdf). 
PORTE, Alain (1992). François Delsarte, une anthologie, Paris, IPMC.

RANDI, Elena (1993). François Delsarte: le leggi del teatro. II pensiero scenico del precursore della danza moderna, Roma, Bulzoni editore.

RANDI, Elena (1996). Il magistero perduto di Delsarte. Dalla Parigi romantica alla modern dance, Padova, Esedra editrice.

RANDI, Elena, BRUNETTI, Simone (2013). I movimenti dell'anima. François Delsarte fra teatro e danza, Bari, Edizioni di Pagina.

RUYTER, Nancy Lee Chalfa (1979). Reformers and visionaries: the Americanization of the Art of Dance, New York, Dance Horizons.

RUYTER, Nancy Lee Chalfa (1991). "Delsarte, son système aux États-Unis », in François Delsarte, 1811-1871. Sources-Pensée, Châteauvallon, Théâtre National de la Danse et de I'Image, p. 33-37.

RUYTER, Nancy Lee Chalfa (1999). The Cultivation of Body and Mind in Nineteenth-Century American Delsartism, Westport Connecticut/ London, Greenwood Press.

SHAVER, Claude L. (1933). The Delsarte System of Expression As Seen Through the Notes of Steele Mackaye, PhD. Dissertation, University of Winsconsin.

SHAVER, Claude L. (1954). "Steele Mackaye and the Delsartean Tradition ", in Karl Wallace, History of Speech Education in America, New York, Appleton-Centery-Crofts, p. 202-218.
SHAWN, Ted (1974). Every Little Movement, a Book about François Delsarte, the Man and his Philosophy, his Science and Applied Aesthetics, the Application of this Science to the Art of the Dance, the Influence of Delsarte on American Dance, Brooklyn, Dance Horizons [1963].

STEBBINS, Genevieve (1977). Delsarte System of Expression, New York, Dance Horizons [1902] (first edition in 1885 with the title Delsarte System of Dramatic Expression).

THOMPSON, Mary S. (1892). "Delsartism in America II: The Relation of Gymnastics to Expression", Werner's Voice Magazine, \# 3, mars, p. 60-61.

WAILLE, Franck (2011a). Corps, arts et spiritualité chez François Delsarte (1811-1871). Des interactions dynamiques, Lille, ANRT [2009] (https://scd-resnum.univ-lyon3.fr/out/theses/2009_out_waille_f.pdf).

WAILLE, Franck (2011b). Trois décennies de recherche européenne sur François Delsarte, Paris, L'Harmattan.

WAILLE, Franck (2016). La méthode somatique expressive de François Delsarte. Histoire, esthétique, anthropologique: de la neurophysiologique à la métaphysique, Montpellier, L'Entretemps.

WAILLE, Franck, DAMOUR, Christophe (ed.) (2015). François Delsarte, une recherche sans fin, Paris, L'Harmattan. 
Recebido: 30/01/2018

Aprovado: 05/02/2018 